Marquette University

e-Publications@Marquette

College of Nursing Faculty Research and

Publications

Nursing, College of

$1-1-2016$

\title{
Exploring Student, Family, and School Predictors of Self-Determination Using NLTS2 Data
}

Karrie A. Shogren

University of Kansas

Mauricio Garnier-Villarreal

Marquette University, mauricio.garniervillarreal@marquette.edu

Chantelle Dowsett

University of Kansas

Todd D. Little

Texas Tech University

Accepted version. Career Development and Transition for Exceptional Individuals, Vol. 39, No. 1 (2016): 23-33. DOI. (C) 2016 Hammill Institute on Disabilities. Used with permission.

Mauricio Garnier-Villareal was affiliated with University of Kansas at the time of publication. 
Marquette University

\section{e-Publications@Marquette}

\section{College of Nursing Faculty Research and Publications/Department of Nursing}

This paper is NOT THE PUBLISHED VERSION; but the author's final, peer-reviewed manuscript.

The published version may be accessed by following the link in the citation below.

Career Development and Transition for Exceptional Individuals, Vol. 39, No. 1 (2014): 23-33. DOI. This article is (C) SAGE publications and permission has been granted for this version to appear in e-Publications@Marquette. SAGE Publications does not grant permission for this article to be further copied/distributed or hosted elsewhere without the express permission from SAGE Publications.

\section{Contents}

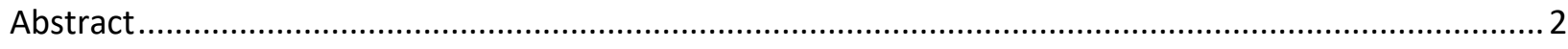

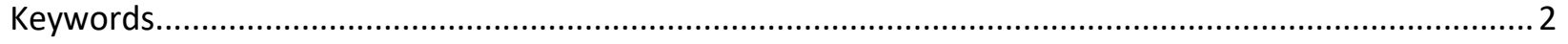

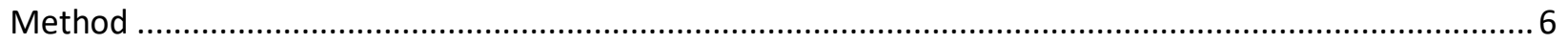

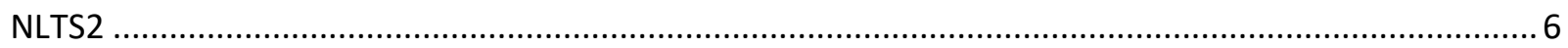

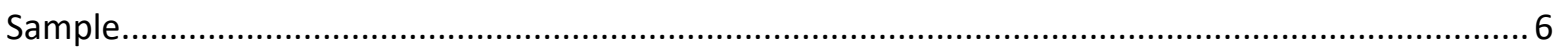

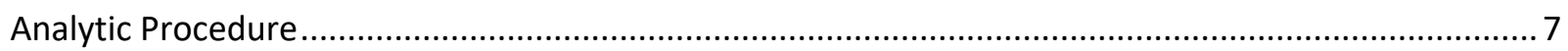

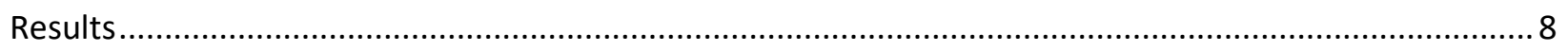

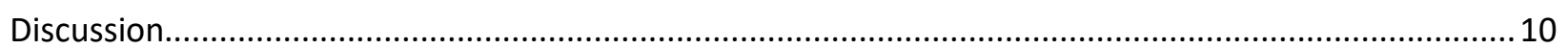

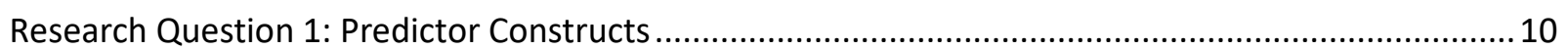

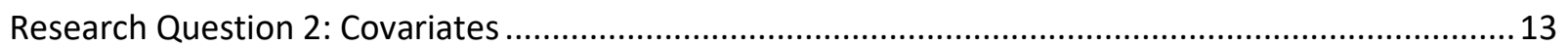

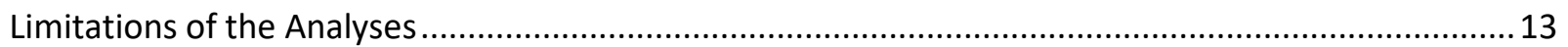

Implications for Future Research and Practice ................................................................... 15

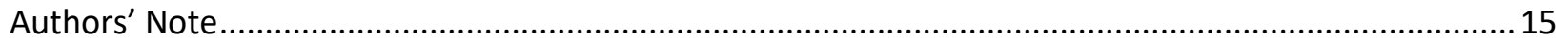

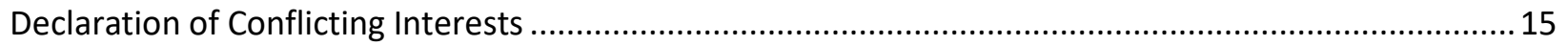

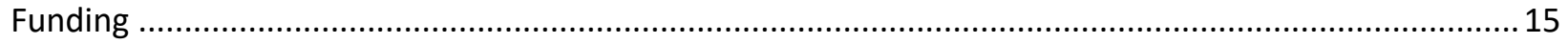

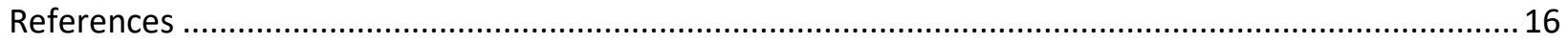




\title{
Exploring Student, Family, and School Predictors of Self-Determination Using NLTS2 Data
}

\author{
Karrie A. Shogren \\ University of Kansas, Lawrence, KS \\ Mauricio Garnier Villarreal \\ University of Kansas, Lawrence, KS \\ Chantelle Dowsett \\ University of Kansas, Lawrence, KS \\ Todd D. Little \\ Texas Tech University, Lubbock, TX
}

\begin{abstract}
This study conducted secondary analysis of data from the National Longitudinal Transition Study-2 (NLTS2) to examine the degree to which student, family, and school constructs predicted self-determination outcomes. Multi-group structural equation modeling was used to examine predictive relationships between 5 student, 4 family, and 7 school constructs developed from NLTS2 data and self-determination outcomes (autonomy, psychological empowerment, and self-realization) across disability groups. The pattern of predictive relationship between the constructs and self-determination outcomes across disability groups was complex. Only one construct-self-concept-showed a positive predictive relationship with all three self-determination constructs across most disability groups. Implications of the complex pattern of findings for research and practice are discussed.
\end{abstract}

Keywords

self-determination, secondary data analysis, NLTS2, transition

Self-determination has received significant attention in the fields of special education and transition. Wehmeyer (2006) defined self-determined behavior as "volitional actions that enable one to act as the primary causal agent in one's life and to maintain or improve one's quality of life" (p. 17). Self-determined behavior refers to actions that are identified by four essential characteristics: (a) the person acts autonomously; (b) the behavior(s) are selfregulated; (c) the person initiates and responds to the event(s) in a psychologically empowered 
manner; and (d) the person acts in a self-realizing manner (Wehmeyer, Abery, Mithaug, \& Stancliffe, 2003). The concepts of causal agency and volitional action are central to this theoretical perspective. Researchers have developed and validated instructional strategies that can be used to promote self-determined behavior (Algozzine, Browder, Karvonen, Test, \& Wood, 2001) and documented strong, positive impacts of instruction in self-determination skills on school and postschool outcomes (Shogren, Wehmeyer, Palmer, Rifenbark, \& Little, in press; Wehmeyer, Palmer, Shogren, Williams-Diehm, \& Soukup, 2013). Relatively little, however, is known about the contextual factors that influence the development of self-determination and interventions to promote it (Shogren, 2013). Contextual factors (namely, student, family, and school factors) have the potential to influence both the development of self-determination and effectiveness of interventions to promote it. For example, student-level factors, such as disability label, may impact the supports students need to develop self-determination skills. Family and school-level factors, such as the beliefs of family members and teachers and the practices adopted at home and school to promote self-determination skills, can also impact the development of self-determination. A student's previous experiences at home and at school can also impact how they respond to interventions (Cook \& Odom, 2013), as can their experiences in school with transition planning and access to general education (Shogren et al., 2007).

Developing a greater understanding of the influence of contextual factors across various ecological systems (i.e., student, family, school, and community; Bronfenbrenner, 1979, 2005) has the potential to allow for a greater understanding of the development of self-determination and best practices in developing individualized interventions that address relevant student, family, and school contextual factors. Empirical work has examined the influence of contextual factors, although the primary focus has been student-level factors. For example, researchers have found differences in self-determination status based on disability label (Carter, Lane, Pierson, \& Glaeser, 2006; Shogren, Kennedy, Dowsett, \& Little, 2013) and gender (Nota, Ferrari, Soresi, \& Wehmeyer, 2007; Shogren et al., 2007). Different patterns of findings, however, have been reported across research teams, perhaps related to differing samples or contextual factors examined. More limited work has examined environmental factors at the family or school level, although this work has documented potential factors of influence, such as family cultural background (Shogren, 2011; Zhang, 2005; Zhang, Wehmeyer, \& Chen, 2005) and opportunities for inclusion and access to the general curriculum (Y. Lee et al., 2012; Zhang, 2001).

Theoretical work (Shogren, 2013; Walker et al., 2011) has argued that a more comprehensive range of contextual factors needs to be considered simultaneously, across ecological systems, to promote a more nuanced understanding of the diverse contextual factors that affect selfdetermination. Such work relies on the social-ecological model of disability (Schalock et al., 2010; World Health Organization, 2007), which acknowledges the interactive effects of personal and environmental factors in shaping the experiences of people with disabilities. For example, rather than only considering student factors (such as disability label) when implementing self-determination interventions, a greater understanding of school-level factors that affect self-determination may provide information on the importance of considering inclusive opportunities or peer attitudes concurrently with implementing self-determination 
interventions. Such work is consistent with the tenants of implementation science, which emphasizes contextual fit (i.e., the fit between research and the context within which research findings will be implemented; Cook \& Odom, 2013).

Empirical research that builds social-ecological models of self-determination by systematically cataloguing student, family, and school factors that impact self-determination is needed, but collecting and systematically analyzing data on a diverse array of contextual factors that affect youth with disabilities can be difficult. However, the availability of data from the National Longitudinal Transition Study-2, which documents the secondary and postschool experiences of a nationally representative sample of youth with disabilities over a 10-year period, provides a unique opportunity to examine factors at the student, family, and school level that impact outcomes, such as self-determination. NLTS2 not only directly assessed student selfdetermination, but it also collected extensive data from students, families, teachers, administrators, and school records on an array of personal and environmental factors. These data provide an opportunity to examine key student, family, and school factors that affect selfdetermination (and other valued educational) outcomes.

In previous work, we examined the impact of disability label (Shogren et al., 2013) and race/ethnicity (Shogren, Kennedy, Dowsett, Garnier Villarreal, \& Little, in press) on selfdetermination using NLTS2 data, documenting the complex interplay between these student factors and three of the four essential characteristics of self-determination (autonomy, selfrealization, and psychological empowerment) defined by Wehmeyer et al. (2003) that were measured in NLTS2. Shogren et al. (2013) found that disability label affected self-determination, but that certain disability groups sampled in NLT2 showed similar patterns of latent means and variances. Of the 12 disability categories recognized by Individuals With Disabilities Education Act (IDEA) at the secondary level, groups of students with high-incidence disabilities (learning disabilities, emotional disturbances, speech or language impairments, and other health impairments), sensory disabilities (visual and hearing impairments), and cognitive disabilities (autism, multiple disabilities, and deaf-blindness) could be created, but students with intellectual disability, traumatic brain injury, and orthopedic impairments could not be collapsed with any other group because of differences in self-determination scores. Even when collapsing groups, there was still significant unexplained variance within and across groups, highlighting the fact that even when accounting for key student-level factors, there are still additional contextual factors that affect self-determination. To this end, we worked with NLT2 data to generate an array of student, family, and school constructs, in addition to disability label, to examine the relationship between contextual factors and self-determination.

As reported by Shogren and Garnier Villarreal (in press), we reviewed NLTS2 data collected during years 1 and 2 of the 10-year study or during the Direct Student Assessment (collected either in Waves 1 or 2 based on student's age) to define student, family, and school constructs. We then identified 16 conceptually and empirically validated constructs ( 5 student, 4 family, and 7 school) that can be examined as predictors of student self-determination (see Table 1 for a description). Our primary motivation for the current article is to examine the degree to which these 16 constructs predict self-determination, to identify which student, family, and school 
factors can potentially be manipulated and enhanced to promote more positive selfdetermination outcomes. Once the strongest predictors of the three essential characteristics of self-determination are identified, educators can target these contextual factors as they are designing and implementing self-determination interventions. To provide insight into relevant factors, we will examine two primary research questions:

Research Question 1: To what degree do the 16 constructs validated by Shogren and Garnier Villarreal (in press) predict the three essential characteristics of selfdetermination (autonomy, self-realization, and psychological empowerment) measured in NLTS2 in students with high-incidence disabilities, cognitive disabilities, sensory disabilities, traumatic brain injury, intellectual disability, and orthopedic impairments?

Research Question 2: To what degree do key covariates (gender, race/ethnicity, and socioeconomic status) affect autonomy, self-realization, and psychological empowerment across groups?

Table 1. Empirically Validated Latent Student, Family, and School NLTS2 Constructs From Shogren and Garnier Villarreal (in press).

Table I. Empirically Validated Latent Student, Family, and School NLTS2 Constructs From Shogren and Garnier Villarreal (in press).

\begin{tabular}{|c|c|}
\hline Constructs & Brief description \\
\hline \multicolumn{2}{|l|}{ Student constructs } \\
\hline Grades & Student GPA across academic, vocational, and other classes \\
\hline Classroom behavior & $\begin{array}{l}\text { Student use of appropriate classroom behavior in vocational domain (asking } \\
\text { for help, staying focused, etc.) }\end{array}$ \\
\hline Functional skills & $\begin{array}{l}\text { Student performance of tasks related to basic mental skills, and community } \\
\text { and daily living skills }\end{array}$ \\
\hline Self-concept & Self-reported confidence in academics and social areas \\
\hline Social and communication skills & Student skills in social interactions and communication \\
\hline \multicolumn{2}{|l|}{ Family constructs } \\
\hline General parent imvolvement & $\begin{array}{l}\text { Parent involvement in general school activities (volunteering, parent/teacher } \\
\text { conferences) and engagement with youth around school activities }\end{array}$ \\
\hline Home independence & Student performance of chores in the household \\
\hline Parent involvement in special education planning & Parent attendance at most recent IEP meeting \\
\hline Parent outcome expectations & $\begin{array}{l}\text { Parent ratings of thelihood of the attainment of postschool outcomes } \\
\text { (employment, independent living, etc.) }\end{array}$ \\
\hline \multicolumn{2}{|l|}{ School constructs } \\
\hline Access to the general curriculum-academics & Student access to core academic subject areas \\
\hline $\begin{array}{l}\text { Access to the general curriculum- } \\
\text { accommodations and modifications }\end{array}$ & $\begin{array}{l}\text { Student access to accommodations and modifications in core academic } \\
\text { subject areas }\end{array}$ \\
\hline Inclusion & Percent of time in general education classroom for academic classes \\
\hline Social networks & Student participation in school, social, and volunteer/community activities \\
\hline Supports & Availability of emotional and formal supports for student \\
\hline Student inwolvement in education planning & Level of student participation in transition planning \\
\hline Vocational experiences & Access to vocational goals, job development, and work experiences \\
\hline
\end{tabular}

Note. NLTS2 = National Longitudinal Transition Scudy-2; GPA " grade point average; IEP = Individualized Educavion Program. 


\section{Method}

We conducted secondary analysis of data from the NLTS2 to examine the degree to which student, family, and school constructs predicted self-determination. In this section, we provide an overview of the NLTS2 data collection, the NLTS2 sample, and data sources used in this study, and the analytic plan.

\section{NLTS2}

NLTS2 was funded by the federal Department of Education to document the experiences of students with disabilities as they transitioned from school to adult life (Wagner, Newman, Cameto, \& Levine, 2006b). It was a follow-up to the original NLTS, conducted from 1987 to 1993 (Wagner, 1992). The contractor, SRI International, began data collection in 2000 with a nationally representative sample of students in the 12 disability categories recognized in the IDEA at the secondary level (i.e., autism, deaf-blindness, emotional disturbance, hearing impairment, learning disability, mental retardation, multiple disabilities, orthopedic impairment, other health impairment, speech and language impairment, traumatic brain injury, and visual impairment). Data collection continued for a 10 -year period in five waves (one wave is 2 years of data collection). Data were gathered from multiple sources, including students, family members, teachers, school administrators, and school records.

To generate a nationally representative sample of students across disability categories, SRI implemented a two-stage sampling plan. First, districts were stratified by geographic region, size, and community wealth; then students were randomly selected within each of the 12 disability categories with a target of 1,250 students per disability category at the first wave of data collection to achieve a sufficient sample at the end of the study (SRI International, 2000

Sample

As described previously, this study is part of a larger research project to examine predictors and outcomes of self-determination using NLTS2 data. NLTS2 directly assessed student's academic and transition-related (e.g., self-determination, self-concept) skills once during the course of the study in either Wave 1 or 2. Students in older age cohorts were sampled in Wave 1 and in younger age cohorts in Wave 2 (Wagner, Newman, Cameto, \& Levine, 2006a). Whereas the majority of the NLTS2 sample participated in the Direct Student Assessment, a small subset of students (approximately 17\%) were deemed unable to participate in a direct testing situation or to be able to meaningfully respond to the questions by their teachers. The number of students who participated in the Direct Assessment varied by disability label, with a high of $98 \%$ of students with learning disabilities and speech language impairments participating to a low of $58 \%$ of students with autism participating (Shogren et al., 2013). Because self-determination was a primary focus in our research, we structured our sample to only include those students who participated in the Direct Assessment. Therefore, the sample for this study is comprised of students deemed able by their teachers to participate in the Direct Student Assessment, using 
NLTS2 sampling weights designed to make valid inferences across disability groups in this nationally representative sample.

Data source-Self-determination outcome constructs

As mentioned previously, self-determination data were collected during the Direct Student Assessment during Waves 1 or 2. Specifically, the Direct Student Assessment included 26 of 72 items from The Arc's Self-Determination Scale (SDS; Wehmeyer \& Kelchner, 1995). The SDS is based on the functional theory of self-determination (Wehmeyer, 2003) and the full scale measures overall self-determination through assessment of the four essential characteristics of self-determined behavior: autonomy, self-regulation, psychological empowerment, and selfrealization. The 26 NLTS2 items only included items from three of the four subscales (Autonomy, Self-Realization, Psychological Empowerment). In previous work, we demonstrated that a three-construct representation of self-determination from NLTS2 data was conceptually and psychometrically sound, but that an overall self-determination construct could not be represented with the existing data. Thus, in the present analyses we chose to represent selfdetermination outcomes as three latent constructs-autonomy, psychological empowerment, and self-realization-using the procedures described in Shogren et al. (2013).

\section{Data source-Predictor constructs}

In the present analysis, 16 social-ecological constructs developed and empirically validated by Shogren and Garnier Villarreal (in press) from NLTS2 data were used to examine the degree to which student, family, and school factors predict student self-determination. The 16 constructs are described in Table 1. The constructs were generated from six NLTS2 data collection instruments: Direct Student Assessment, Parent Telephone Interview, School Characteristics Survey, School Program Survey, Teacher Survey, and Transcript Records. All of the predictor constructs were generated from data collected in Wave 1 or during the student's ninth grade year (for Transcript Records), with the exception of the Direct Student Assessment that was collected in Wave 1 or 2 based on student age, as described previously. Respondents included student, parents, or family members, teachers, and administrators; data were also collected from student transcript records. Further information and examples of the data collection instruments can be found at http://www.nlts2.org/studymeth/\#data_collection. The specific NLTS2 variables used to build the 16 predictor constructs are described in detail in Shogren and Garnier Villarreal (in press).

We also included key covariates in the model-gender (male/female; w2_Gend2), race/ethnicity (White, Black, Hispanic, Other; w2_Eth6), and family income (16 possible responses, from US\$5,000 to US\$75,000 by increments of US\$5,000; np1K15Detail) - to examine their relationship with predictors and self-determination outcomes.

\section{Analytic Procedure}

To examine the degree to which the 16 student, family, and school constructs validated through confirmatory factor analysis by Shogren and Garnier Villarreal (in press) predicted the three essential characteristics of self-determination (autonomy, self-realization, and 
psychological empowerment), we used multiple-group structural equation modeling (Brown, 2006; Kline, 2010; Little, 2013). We used six disability groups established in previous work (Shogren et al., 2013): high-incidence disabilities (learning disabilities, emotional disturbances, speech or language impairments, and other health impairments), sensory disabilities (visual and hearing impairments), cognitive disabilities (autism, multiple disabilities, and deaf-blindness), intellectual disability, traumatic brain injury, and orthopedic impairments. Mplus, version 7 (Muthén \& Muthén, 1998-2010) with the "type=complex" option and the "wt_na" sampling weight, stratum, and cluster variables for the complex sampling design was used for all analyses.

Using the final model from the multi-group confirmatory factor analyses of the 16 predictor constructs (see Shogren \& Garnier Villarreal, in press, for information on the relevant factor loadings and evaluation of model fit, including information on the use of root mean square error approximation [RMSEA] and standardized root mean residual [SRMR] to evaluate model fit because of low correlations between certain indicators; Taylor, 2008), we converted the correlational relationships between the 16 predictor and 3 self-determination outcome constructs to predictive paths. After all the possible prediction paths were estimated, we used a $\chi^{2}$ difference test to determine which paths were significant predictors for each disability group, with a cutoff of $p<.01$. After establishing the relevant prediction paths, we added covariates to the model (gender, family income, and race/ethnicity) to address Research Question 2 . The covariates were added as semi-partial covariates, meaning that the effect of the covariates was first removed from the dependent constructs (self-determination), then the covariate effects were tested for significance ( $\chi^{2}$ difference test), and only the relevant prediction paths were kept (Little, 2013).

\section{Results}

The baseline model for the present analyses was the final partial strong invariance model from the multi-group confirmatory factor analysis of the 16 predictor constructs and 3 selfdetermination outcomes described by Shogren and Garnier Villarreal (in press). This model demonstrated adequate fit $\chi^{2}(7927, n=5240)=24563.69$, RMSEA $=0.049(0.048,0.050)$, SRMR $=0.061$, non-normed fit index $(\mathrm{NNFI})=0.771$, comparative fit index $(\mathrm{CFI})=0.796$ using criteria established by Taylor (2008) for secondary analysis of data sets where some indicators have low correlational relationships. To address Research Question 1, the correlational paths between the student, family, and school constructs and self-determination outcome constructs were converted to regression paths. Table 2 shows the significant latent regression paths between the student, family, and school factors and the self-determinations constructs across disability groups. When a regression path was non-significant, it was fixed to zero, which is designated in Table 2 by a blank cell. One student-level predictor, self-concept, was significant across most disability groups and outcome constructs with the exception of autonomy for students with sensory disabilities and psychological empowerment for students with intellectual and cognitive disability. Generally, students who reported having higher self-concept also tend to report higher autonomy, self-realization, and psychological empowerment, with effects ranging from 0.50 to 0.83 . Interestingly, as described by Shogren and Garnier Villarreal (in press), self- 
concept was the only construct (apart from the self-determination outcome constructs) that was measured in the Direct Student Assessment using questions from an established scale with reliability and validity data. There were 13 predictor constructs that did not demonstrate any significant relationships with self-determination outcome constructs across groups -2 were student-level factors; 3 were family-level factors; and 5 were school constructs.

Table 2. Significant Regression Paths to the Self-Determinations Constructs Across the Disability Groups (Standardized Solution).

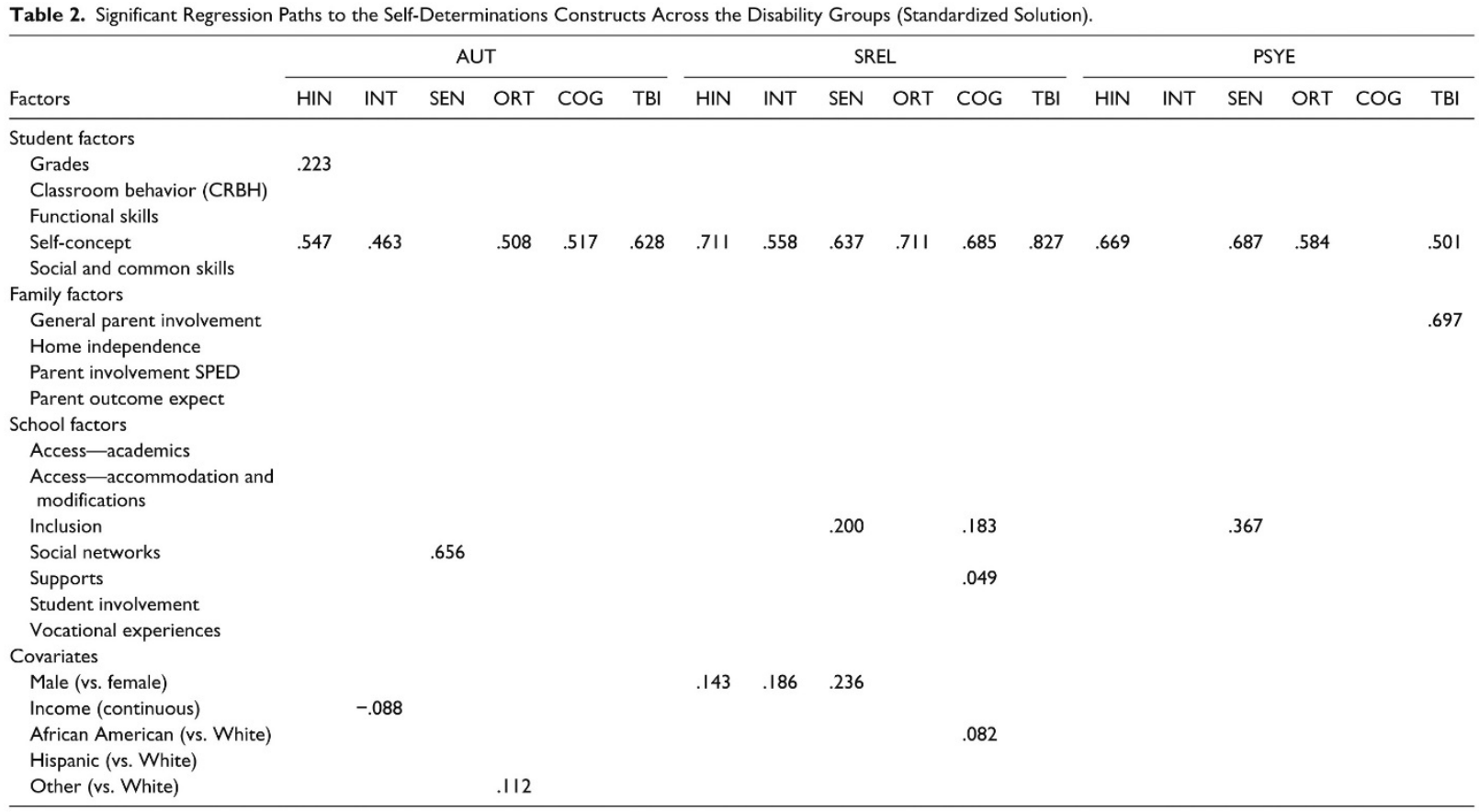

Note. AUT = autonomy; SREL = self-realization; PSYE = psychology empowerment; HIN = high incidence disabilities; INT = intellectual disability; SEN = sensory disabilities; ORT = orthopedic impairments; $\mathrm{TBI}=$ traumatic brain injury; SPED = special education.

For the latent autonomy self-determination outcome construct, apart from self-concept, student grades were a positive predictor of autonomy in the high-incidence disability groups and social networks were a strong predictor of autonomy for youth with sensory disabilities. The self-realization and psychological empowerment constructs also had significant predictors in additional to self-concept. For example, among youth with cognitive disabilities there were significant regression paths between inclusion and supports and self-realization, and for youth with sensory disabilities there was also a significant path from inclusion to self-realization. Inclusion was also a significant predictor of psychological empowerment for youth with sensory disabilities, and general parent involvement for youth with traumatic brain injury.

In terms of Research Question 2, there was a diverse pattern of predictive relationship between the covariates and self-determination outcome constructs across disability groups. In terms of gender, males tended to score higher in self-realization in the high-incidence, intellectual, and sensory disability group. In terms of income, there was a negative relationship between income and autonomy in the intellectual disability group. For race/ethnicity, Hispanic youth did not 
differ from their White counterparts on any of the constructs. African American students with cognitive disability, however, tended to score slightly higher in self-realization, and students in the "Other" category tended to score slightly higher in autonomy in the orthopedic impairment group.

\section{Discussion}

This article examined the degree to which student, family, and school factors predicted three essential characteristics of self-determination (autonomy, self-realization, and psychological empowerment) measured in NLTS2 across diverse disability groups. The pattern of predictive relationship between the constructs and self-determination outcomes across disability groups was complex, but provides direction for future research and practice by adding to the empirical literature on social-ecological models of self-determination research and intervention by identifying student, family, and school factors that impact adolescent's self-reported levels of self-determination. In this section, we discuss findings specific to each of the two research questions, limitations, and implications for future research and practice.

\section{Research Question 1: Predictor Constructs}

The pattern of predictive relationship between the 16 student, family, and school-level constructs and self-determination outcomes across disability groups was limited, although the significant paths provide insights for future research and practice. As mentioned in the results, only one construct-self-concept-showed a positive predictive relationship with all three selfdetermination constructs across most disability groups. This finding suggests a strong positive relationship between self-concept and self-determination, which necessitates future research on the shared elements of the two constructs and interventions to promote them.

Furthermore, the fact that self-concept and the self-determination constructs were the only constructs in the models generated from student self-report suggests that future research needs to consider the influence of both measurement-related factors as well as the strong relationships between student's perceptions of their own competence and how constructs like self-concept and self-determination may interact. Self-determination has already been situated in the broader field of positive psychology (Shogren, Wehmeyer, Pressgrove, \& Lopez, 2006; Wehmeyer, 2013), as has self-concept research (Snyder \& Lopez, 2002), and although other positive psychological constructs (e.g., hope, optimism, life satisfaction) were not measured in NLTS2, the findings suggest the importance of future research examining the relationships between strength-based constructs and outcomes, such as self-determination.

The differing patterns of relationships between predictor constructs and outcomes across disability groups highlights the interaction between disability and other student, family, and school-level factors, and autonomy, self-realization, and psychological empowerment outcomes. Ultimately, it suggests that situating self-determination within a social-ecological perspective affords an opportunity to bring increased attention to the person-environment interaction, specifically the complex interplay between various ecological systems (Shogren, 2013). It also highlights the importance of, at the individual student level, working to understand the diverse array of contextual factors that influences youth development and 
outcomes (Bronfenbrenner, 2005). The most important contextual factors are likely going to be defined on an individual basis, as each student has a unique profile of disability-related needs and demographic characteristics. Strategies need to be developed to support practitioners in identifying the most relevant contextual factors for students based on each student's unique profile and goals for the future. Ultimately, the self-determination and its development is complex, and this complexity operates at the individual level, making it even more difficult to study and develop and evaluate interventions to support its development.

In terms of overall patterns, student involvement was, unexpectedly, a non-significant predictor of the self-determination outcome constructs across groups. Promoting student involvement is routinely cited in the literature as best practice (Martin et al., 2006; Test et al., 2009), although empirical research linking it directly with self-determination outcomes is limited. The lack of relationships may be related to measurement issues, as discussed in the Limitations, or may be related to the lack of high-quality experiences or supports available to many students with disabilities, including those with more significant support needs to facilitate student involvement (Martin, Huber Marshall, \& Sale, 2004). Further research is needed to examine the impact of student involvement, the interaction of student involvement, and family/student preferences, and the best ways to promote it across ecological contexts.

In terms of parent involvement, general parent involvement showed a significant relationship with psychological empowerment in students with traumatic brain injuries, but not in any other groups although as noted for student involvement, this may have been because of the restricted definition of this construct based on available NLTS2 data. Past research (Sands, Spencer, Gliner, \& Swaim, 1999) suggests positive outcomes resulting from parent involvement, and further research is needed on the degree to which youth perceive parent involvement as helpful and positive for their development as well as parent skills and attitudes regarding involvement, which may vary based on their background and beliefs about disability. For example, research indicates that greater parental involvement with homework can significantly benefit youth with high-incidence disabilities in developing self-confidence (Bryan, Burstein, \& Bryan, 2001; Zimmerman \& Kitsantas, 2005), and perhaps parent involvement predicts selfconcept (which was not tested here). Parent involvement, however, can also have deleterious effects, particularly when it leads to negative interactions between youth or parents and/or is based in a deficit model of disability (Bryan et al., 2001). These complex relationships may not have been fully captured in our analyses, and further research is needed on strategies to promote parent involvement across ecological systems and student perceptions of parent involvement.

Social networks, defined by student participation in school and community activities, showed a significant positive relationship with autonomy for students with sensory disabilities. This finding suggests that social networks can significantly impact autonomy for youth with sensory disabilities, and this finding is congruent with the focus on inclusion and the argument for the importance of peer relations and supports for the growth and development of youth with and without disabilities (Siperstein, Norins, \& Mohler, 2007; Walker et al., 2011). Further research is needed on the roles of social networks, and how to promote these networks. For example, 
research suggests that youth with disabilities tend to have fewer members in their social networks (Farmer et al., 2011), and perhaps this explains the limited relationship between selfdetermination and social outcomes.

Inclusion also showed relationships with self-realization and psychological empowerment for youth with sensory disabilities and with self-realization for youth with cognitive disabilities. And, grades showed a significant relationship with autonomy for youth with high-incidence disabilities. Furthermore, supports showed a positive relationship with self-realization for youth with cognitive disabilities. These patterns of findings suggest that success (achieving high grades) in inclusive settings with peers with needed supports can impact self-determination outcomes. Perhaps because youth with high-incidence disabilities are more likely to be included, outcomes are more strongly related to greater autonomy for them, but for youth with cognitive and intellectual disability, access and supports are more important to promoting empowerment and self-realization. This is congruent with previous research that has suggested a relationship between access, supports, and self-determination (S. H. Lee, Soukup, Little, \& Wehmeyer, 2009; S. H. Lee, Wehmeyer, Soukup, \& Palmer, 2010; Shogren, Palmer, Wehmeyer, Williams-Diehm, \& Little, 2012), and further highlights the need to consider these factors concurrently. Implementing self-determination interventions in inclusive, academic settings may lead to a more significant impact on self-determination outcomes, particularly if appropriate supports are provided for youth with low-incidence disabilities. The development of interventions that are relevant for students with and without disabilities, and can be overlaid on academic activities by promoting goal-setting, choice-making, and self-awareness will be an important avenue for future researchers. The relevance of high expectations must also be considered in future research, it is likely that inclusion may impact self-determination both through access as well as expectations. Expectations may play a role, particularly for students with cognitive and intellectual disability, in determining placement and determinations regarding academic and vocational curriculum content (Wehmeyer, Lattin, \& Agran, 2001).

Ultimately, these findings suggest that factors related to inclusion, grades social networks, supports, and parent involvement all play a role in the development and expression of selfdetermination. Further research, however, is needed to explore more deeply the diverse results and distinguish among those that are meaningful for intervention and those that are not. For example, parent involvement may function in different ways depending on the reasons parents are involved (e.g., because of challenges with the school system or to build strong parent-child relationships). Access to general education may also promote positive outcomes so long as youth have strong social networks and are held to high expectations in those settings. To understand self-determination and the impact of interventions to promote self-determination, understanding the ways that these factors are experienced by youth with disabilities will be important. In practice, strategies to collect individual and ecological data prior to implementing interventions or supports to promote self-determination may assist teachers and schools with (a) selecting the most relevant intervention given contextual factors and (b) to assess and understand the factors that impact the effect of the intervention. 


\section{Research Question 2: Covariates}

As with the predictor constructs, the findings related to covariates provide additional information that help decompose differences that other research teams have found based on student-level factors. For example, with regard to gender, the main differences were found in the self-realization construct, with males tending to score higher in multiple disability groups. Further work is needed to examine why males show higher levels of self-realization in adolescence, and it is important to note that the findings may be concentrated in this construct. Previous work has primarily looked for differences in overall self-determination (Shogren et al., 2007; Soresi, Nota, \& Wehmeyer, 2007).

Self-determination researchers rarely collect socioeconomic data and analyze its impact (Algozzine et al., 2001; Wood, Fowler, Uphold, \& Test, 2005). Interestingly, our proxy for SESfamily income-only showed an impact in the intellectual disability group for autonomy, and the relationship was negative (higher autonomy in lower income families). It may be that youth in lower income environments may have demands placed on them to develop strong skills related to being autonomous, but this finding should be considered preliminary.

In terms of race/ethnicity, African American youth with intellectual disability tended to report slightly higher levels of self-realization. This finding is consistent with previous work suggesting that African American youth tended to report higher levels of empowerment (Shogren, Kennedy, et al., in press). This finding highlights the impact that looking comprehensively and empirically at the combined influence of multiple factors can have on outcomes. Research is needed that examines the experiences of African American youth, and the contextual factors that shape experiences (Shogren, 2011). Finally, researchers rarely study the experiences of youth with orthopedic impairments from other race/ethnicity groups, and further research examining the family and community factors that influence these findings is needed.

\section{Limitations of the Analyses}

Any secondary data analysis is impacted by the data available to conduct the secondary analysis. NLTS2 provides unparalleled access to broad information on the secondary and postschool outcomes of youth with disabilities. It is important to note, however, that the primary focus of NLTS2, particularly in the parent, teacher, and youth surveys, was the inclusion of individual survey items. Given our focus on examining latent constructs representing key individual and ecological factors, there are challenges in using the NLTS2 data to construct social-ecological models of self-determination. Specifically, latent constructs that are both conceptually and empirically sound have to be constructed from the NLTS2 data, and as described in Shogren and Garnier Villarreal (in press) there were several constructs we had hoped to develop and include in our social-ecological models that either were not conceptually represented in the data, or did not withstand empirical testing. For example, we had hoped to include constructs related to parents' beliefs about self-determination, but questions specific to this area were not included in NLTS2. 
We had also hoped to create latent constructs on parent and student involvement in transition planning. But, although several items were included in NLTS2, these items did not hang together in a way that allowed for the development of robust latent constructs to represent the diverse facets of these constructs. For parent involvement, a single indicator on attendance at the last Individualized Education Program (IEP) meeting was the only way to represent the construct, and for student involvement, a single indicator of student level of participation in their last IEP meeting as judged by a teacher was the only way to represent it, despite additional items being included in NLTS2 (Shogren \& Garnier Villarreal, in press); these additional items did not demonstrate good model fit when they were grouped together. Therefore, constructs used in these analyses fail to consider factors other than attendance and involvement, such as access to supports, instruction on how to participate in their meeting, and student and family preferences on level of involvement. For this reason, the predictive relationships identified in our models must be viewed as preliminary, and not necessarily encompassing the totality of any construct or social-ecological model.

Future research is needed to construct scales that robustly measure constructs, such as student involvement, that are hypothesized to be central to promoting self-determination and transition outcomes (Test et al., 2009), as past research has suggested that simplistic representations (i.e., attendance alone) does not predict outcomes, instead it is the degree to which empowerment results from being engaged in the planning process (Shogren et al., 2007). In the present analyses, it is likely factors related to the variables included in the latent constructs influenced the pattern of relationships, and may explain the lack of impact of some constructs. The impact of measurement issues must be considered in interpreting the findings.

In addition, because the focus of NLTS2 was on school-based experiences, the data collected on family and community factors was more limited, which restricted our ability to fully consider these factors in our social-ecological models. Furthermore, although a social-ecological conceptualization of self-determination suggests a nested data structure and the need for multi-level analyses, NLTS2 did not include variables that allowed for nested analyses (e.g., which students were sampled from the same schools). Future research should explore the pattern of predictive relationships when information is available to perform multi-group, multilevel structural equation modeling (SEM). Finally, because our focus was self-determination outcomes, our sample was restricted to those who were able to participate in the Direct Student Assessment, which means that the results are not generalizable to students who did not participate in the direct assessment and likely had more significant cognitive disabilities. Further research is needed both on assessing self-determination in this population, as well as on the factors that impact its growth and development. In many ways, the current analyses should be viewed as a starting point in the process of identifying key contextual factors. Further research is needed on additional factors, additional strategies to measure contextual factors, and models on how to individualize analysis of such factors for specific student, family, and school contexts. 


\section{Implications for Future Research and Practice}

Ultimately, the present analyses suggest the complexity of the mechanisms through which individual and ecological factors impact self-determination in youth with disabilities. These findings suggest a strong relationship between student perceptions of their competence and self-determination outcomes, as well as combined and interactive effects of multiple student, family, and school factors on self-determination. In practice, this complexity suggests that simply matching a self-determination intervention to disability label or to a school program will fail to address the multiple factors that influence the development of self-determination and interventions to promote its efficacy. Such intervention attempts may reach some students, perhaps even a majority, but they will fail to reach students who experience factors not congruent with those that influenced the selection of the intervention or support (e.g., racial/ethnic or socioeconomic diversity). Instead, research is needed to create systematic strategies that allow for the assessment and cataloguing of multiple factors that impact selfdetermination, including factors in the school and community context that matter to individual students and their families.

Research is also needed on how to embed self-determination within other social-ecological approaches that are increasingly being adopted in school and adult service systems, such as inclusion, access to the general education curriculum, positive behavior supports, and problemsolving response to intervention (RTI) models (Sailor, 2009; Sailor, Dunlop, Sugai, \& Horner, 2009). Carefully assessing self-determination and building an understanding of the contextual factors that impact each student will allow for the individualization of self-determination interventions based on key contextual factors. Only through such research and practice can social-ecological models of self-determination be systematically developed and implemented to improve outcomes for all students.

\section{Authors' Note}

The opinions expressed are those of the authors and do not represent views of the Institute or the U.S. Department of Education.

\section{Declaration of Conflicting Interests}

The author(s) declared no potential conflicts of interest with respect to the research, authorship, and/or publication of this article.

\section{Funding}

The author(s) disclosed receipt of the following financial support for the research, authorship, and/or publication of this article: The research reported here was supported by the Institute of Education Sciences, U.S. Department of Education, through Grant R324A110041 to the University of Kansas. 


\section{References}

Algozzine, B., Browder, D., Karvonen, M., Test, D. W., Wood, W. M. (2001). Effects of interventions to promote self-determination for individuals with disabilities. Review of Educational Research, 71, 219-277. doi:10.3102/00346543071002219

Bronfenbrenner, U. (1979). The ecology of human development: Experiments by nature and design. Cambridge, MA: Harvard University Press.

Bronfenbrenner, U. (Ed.). (2005). Making human beings human: Bioecological perspectives on human development. Thousand Oaks, CA: SAGE.

Brown, T. A. (2006). Confirmatory factor analysis for applied research. New York, NY: Guilford Press.

Bryan, T., Burstein, K., Bryan, J. (2001). Students with learning disabilities: Homework problems and promising practices. Educational Psychologist, 36, 167-180. doi:10.1207/s15326985ep3603_3

Carter, E. W., Lane, K. L., Pierson, M. R., Glaeser, B. (2006). Self-determination skills and opportunities of transition-age youth with emotional disturbance and learning disabilities. Exceptional Children, 72, 333-346.

Cook, B. G., Odom, S. (2013). Evidence-based practices and implementation science in special education. Exceptional Children, 79, 135-144.

Farmer, T. W., Leung, M. C., Weiss, M. P., Irvin, M. J., Meece, J. L., Hutchins, B. C. (2011). Social network placement of rural secondary students with disabilities: Affiliation and centrality. Exceptional Children, 78, 24-38.

Kline, R. B. (2010). Principles and practice of structural equation modeling (3rd ed.). New York, NY: Guilford Press.

Lee, S. H., Soukup, J. H., Little, T. D., Wehmeyer, M. L. (2009). Student and teacher variables contributing to access to the general education curriculum for students with intellectual and developmental disabilities. The Journal of Special Education, 43, 29-44. doi:10.1177/0022466907313449

Lee, S. H., Wehmeyer, M. L., Soukup, J H., Palmer, S. B. (2010). Impact of curriculum modifications on access to the general education curriculum for students with disabilities. Exceptional Children, 76, 213-233.

Lee, Y., Wehmeyer, M. L., Palmer, S. B., Williams-Diehm, K., Davies, D. K., Stock, S. E. (2012). Examining individual and instruction-related predictors of the self-determination of students with disabilities: Multiple regression analyses. Remedial and Special Education, 33, 150-161. doi:10.1177/0741932510392053

Little, T. D. (2013). Longitudinal structural equation modeling. New York, NY: Guilford Press.

Martin, J. E., Huber Marshall, L., Sale, P. (2004). A 3-year study of middle, junior, high, and high school IEP meetings. Exceptional Children, 70, 285-297.

Martin, J. E., van Dycke, J. L., Christensen, W. R., Greene, B. A., Gardner, J. E., Lovett, D. L. (2006). Increasing student participation in IEP meetings: Establishing the self-directed IEP as an evidenced-based practice. Exceptional Children, 72, 299-316.

Muthén, L. K., Muthén, B. O. (1998-2010). Mplus user's guide (6th ed.). Los Angeles, CA: Author.

Nota, L., Ferrari, L., Soresi, S., Wehmeyer, M. L. (2007). Self-determination, social abilities and the quality of life of people with intellectual disability. Journal of Intellectual Disability Research, 51, 850865. doi:10.1111/j.1365-2788.2006.00939.x

Sailor, W. (2009). Making RTI work: How smart schools are reforming education through schoolwide response-to-intervention models. San Francisco, CA: Jossey-Bass.

Sailor, W., Dunlop, G., Sugai, G., Horner, R. (2009). Handbook of positive behavior support. New York, NY: Springer. 
Sands, D. J., Spencer, K. C., Gliner, J. A., Swaim, R. (1999). Structural equation modeling of student involvement in transition-related actions: The path of least resistance. Focus on Autism and Other Developmental Disabilities, 14, 17-27. doi:10.1177/108835769901400103

Schalock, R. L., Borthwick-Duffy, S., Bradley, V., Buntix, W. H. E., Coulter, D. L., Craig, E. P. M., . . Yeager, M. H. (2010). Intellectual disability: Definition, classification, and systems of support (11th ed.). Washington, DC: American Association on Intellectual and Developmental Disabilities.

Shogren, K. A. (2011). Culture and self-determination: A synthesis of the literature and directions for future research and practice. Career Development for Exceptional Individuals, 34, 115-127. doi:10.1177/0885728811398271

Shogren, K. A. (2013). A social-ecological analysis of the self-determination literature. Intellectual and Developmental Disabilities, 51, 496-511. doi:10.1352/1934-9556-51.6.496

Shogren, K. A., Garnier Villarreal, M. (in press). Developing student, family, and school constructs from NTLS2 data. The Journal of Special Education. Advance online publication. doi:10.1177/0022466913513336

Shogren, K. A., Kennedy, W., Dowsett, C., Garnier Villarreal, M., Little, T. D. (in press). Exploring essential characteristics of self-determination for diverse students using data from NLTS2. Career Development and Transition for Exceptional Individuals. Advance online publication. doi:10.1177/2165143413486927

Shogren, K. A., Kennedy, W., Dowsett, C., Little, T. D. (2013). Autonomy, psychological empowerment, and self-realization: Exploring data on self-determination from NLTS2. Exceptional Children, 80, 221-235.

Shogren, K. A., Palmer, S. B., Wehmeyer, M. L., Williams-Diehm, K., Little, T. D. (2012). Effect of intervention with the Self-Determined Learning Model of Instruction on access and goal attainment. Remedial and Special Education, 33, 320-330. doi:10.1177/0741932511410072

Shogren, K. A., Wehmeyer, M. L., Palmer, S. B., Rifenbark, G. G., Little, T. D. (in press). Relationships between self-determination and postschool outcomes for youth with disabilities. The Journal of Special Education. Advance online publication. doi:10.1177/0022466913489733

Shogren, K. A., Wehmeyer, M. L., Palmer, S. B., Soukup, J. H., Little, T. D., Garner, N., Lawrence, M. (2007). Examining individual and ecological predictors of the self-determination of students with disabilities. Exceptional Children, 73, 488-509.

Shogren, K. A., Wehmeyer, M. L., Pressgrove, C. L., Lopez, S. J. (2006). The application of positive psychology and self-determination to research in intellectual disability: A content analysis of 30 years of literature. Research and Practice for Persons With Severe Disabilities, 31, 338-345.

Siperstein, G. N., Norins, J., Mohler, A. (2007). Social acceptance and attitude change: Fifty years of research. New York, NY: Springer.

Snyder, C. R., Lopez, S. J. (Eds.). (2002). Handbook of positive psychology. London, England: Oxford University Press.

Soresi, A., Nota, L., Wehmeyer, M. L. (2007). Self-determination, social abilities, and the quality of life of people with intellectual disabilities. Journal of Intellectual Disability Research, 51, 850-865.

SRI International. (2000). National Longitudinal Transition Study-2 (NLTS2): Study design, timeline and data collection plan. Menlo Park, CA: Author.

Taylor, A. B. (2008). Two new methods of studying the performance of SEM fit indicators (Unpublished doctoral dissertation). Arizona State University, Phoenix.

Test, D. W., Mazzotti, V. L., Mustian, A. L., Fowler, C. H., Kortering, L., Kohler, P. (2009). Evidence-based secondary transition predictors for improving postschool outcomes for students with disabilities. Career Development for Exceptional Individuals, 32, 160-181.

doi:10.1177/0885728809346960 
Wagner, M. (1992). Analytic overview: NLTS design and longitudinal analysis approach. In Wagner, M., D’Amico, R., Marder, C., Newman, L., Blackorby, J. (Eds.), What happens next? Trends in postschool outcomes of youth with disabilities: The second comprehensive report from the National Longitudinal Transition Study of special education students (pp. 2.1-2.14). Menlo Park, CA: SRI International.

Wagner, M., Newman, L., Cameto, R., Levine, P. (2006a). The academic achievement and functional performance of youth with disabilities (A report of findings from the National Longitudinal Transition Study-2 [NLTS2]). Menlo Park, CA: SRI International.

Wagner, M., Newman, L., Cameto, R., Levine, P. (2006b). An overview of findings from Wave 2 of the National Longitudinal Transition Study-2 (NLTS2). Menlo Park, CA: SRI International.

Walker, H. M., Calkins, C., Wehmeyer, M. L., Walker, L., Bacon, A., Palmer, S. B., . . Johnson, D. R. (2011). A social-ecological approach to promote self-determination. Exceptionality, 19, 6-18. doi:10.1080/09362835.2011.537220

Wehmeyer, M. L. (2003). A functional theory of self-determination: Model overview. In Wehmeyer, M. L., Abery, B., Mithaug, D. E., Stancliffe, R. (Eds.), Theory in self-determination: Foundations for educational practice (pp. 182-201). Springfield, IL: Charles C. Thomas Publishing.

Wehmeyer, M. L. (2006). Self-determination and individuals with severe disabilities: Re-examining meanings and misinterpretations. Research and Practice for Persons With Severe Disabilities, 30, 113-120. doi:10.2511/rpsd.30.3.113

Wehmeyer, M. L. (Ed.). (2013). The Oxford handbook of positive psychology and disability. Oxford, UK: Oxford University Press.

Wehmeyer, M. L., Abery, B., Mithaug, D. E., Stancliffe, R. (2003). Theory in self-determination: Foundations for educational practice. Springfield, IL: Charles C. Thomas Publishing.

Wehmeyer, M. L., Lattin, D., Agran, M. (2001). Achieving access to the general curriculum for students with mental retardation: A curriculum decision-making model. Education and Training in Mental Retardation and Developmental Disabilities, 36, 327-342.

Wehmeyer, M. L., Kelchner, K. (1995). The Arc's Self-Determination Scale. Arlington, TX: The Arc National Headquarters.

Wehmeyer, M. L., Palmer, S. B., Shogren, K. A., Williams-Diehm, K., Soukup, J. (2013). Establishing a causal relationship between interventions to promote self-determination and enhanced student self-determination. The Journal of Special Education, 46, 195-210.

doi:10.1177/0022466910392377

Wood, W. M., Fowler, C. H., Uphold, N., Test, D. W. (2005). A review of self-determination interventions with individuals with severe disabilities. Research and Practice for Persons With Severe Disabilities, 30, 121-146. doi:10.2511/rpsd.30.3.121

World Health Organization. (2007). International classification of functioning, disability and health: Children and youth version. Geneva, Switzerland: Author.

Zhang, D. (2001). Self-determination and inclusion: Are students with mild mental retardation more selfdetermined in regular classrooms? Education and Training in Mental Retardation and Developmental Disabilities, 36, 357-362.

Zhang, D. (2005). Parent practices in facilitating self-determination skills: The influences of culture, socioeconomic status, and children's special education status. Research and Practice for Persons With Severe Disabilities, 30, 154-162. doi:10.2511/rpsd.30.3.154

Zhang, D., Wehmeyer, M. L., Chen, L.-J. (2005). Parent and teacher engagement in fostering the selfdetermination of students with disabilities: A comparison between the United States and the Republic of China. Remedial and Special Education, 26, 55-64. doi:10.1177/07419325050260010701 
Zimmerman, B. J., Kitsantas, A. (2005). Homework practices and academic achievement: The mediating role of self-efficacy and perceived responsibility beliefs. Contemporary Educational Psychology, 30, 397-417. doi:10.1016/j.cedpsych.2005.05.003 